\title{
Ultra-processed foods have the worst nutrient profile, yet they are the most available packaged products in a sample of New Zealand supermarkets
}

\author{
Claire M Luiten ${ }^{1}$, Ingrid HM Steenhuis ${ }^{1}$, Helen Eyles ${ }^{2}$, Cliona Ni Mhurchu ${ }^{2}$ and \\ Wilma E Waterlander ${ }^{2, *}$ \\ 'Department of Health Sciences and the EMGO Institute for Health and Care Research, Faculty of Earth and Life \\ Sciences, VU University Amsterdam, Amsterdam, The Netherlands: ${ }^{2}$ National Institute for Health Innovation, School \\ of Population Health, Tamaki Campus, The University of Auckland, Private Bag 92019, Auckland Mail Centre, \\ Auckland 1142, New Zealand
}

Submitted 6 February 2015: Final revision received 13 June 2015: Accepted 17 June 2015: First published online 29 July 2015

\begin{abstract}
Objective: To examine the availability of packaged food products in New Zealand supermarkets by level of industrial processing, nutrient profiling score (NPSC), price (energy, unit and serving costs) and brand variety.

Design: Secondary analysis of cross-sectional survey data on packaged supermarket food and non-alcoholic beverages. Products were classified according to level of industrial processing (minimally, culinary and ultra-processed) and their NPSC.

Setting: Packaged foods available in four major supermarkets in Auckland, New Zealand.

Subjects: Packaged supermarket food products for the years 2011 and 2013.

Results: The majority (84\% in 2011 and 83\% in 2013) of packaged foods were classified as ultra-processed. A significant positive association was found between the level of industrial processing and NPSC, i.e. ultra-processed foods had a worse nutrient profile (NPSC $=11.63$ ) than culinary processed foods $(\mathrm{NPSC}=7 \cdot 95)$, which in turn had a worse nutrient profile than minimally processed foods (NPSC $=3.27$ ), $P<0 \cdot 001$. No clear associations were observed between the three price measures and level of processing. The study observed many variations of virtually the same product. The ten largest food manufacturers produced $35 \%$ of all packaged foods available. Conclusions: In New Zealand supermarkets, ultra-processed foods comprise the largest proportion of packaged foods and are less healthy than less processed foods. The lack of significant price difference between ultra- and less processed foods suggests ultra-processed foods might provide time-poor consumers with more value for money. These findings highlight the need to improve the supermarket food supply by reducing numbers of ultra-processed foods and by reformulating products to improve their nutritional profile.
\end{abstract}

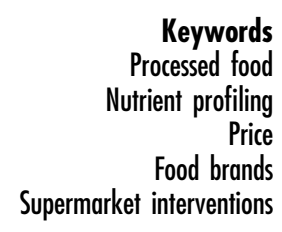

Unhealthy diets play a central role in the onset of noncommunicable disease. Approximately $11 \%$ of disabilityadjusted life years in New Zealand (NZ) are attributable to the effects of poor diets ${ }^{(1,2)}$. Even modest improvements in diet could have a major impact on health if they are adopted by much of the population ${ }^{(3,4)}$. One particular food group of concern is processed foods. Evidence indicates that higher levels of processing are related to decreasing healthiness of foods ${ }^{(5)}$. Nevertheless, sales of processed foods have increased rapidly; these foods currently account for approximately three-quarters of total world food sales (total \$US 3.2 trillion in sales) ${ }^{(6)}$ and contribute between $40 \%$ and $75 \%$ of the energy and nutrients consumed in developed countries ${ }^{(7,8)}$.

Improving diets is a priority for public health, and effective and sustainable interventions are urgently needed. There is clear evidence showing that promotional campaigns are minimally effective ${ }^{(9)}$ and that research should be looking into the design of the food environment to achieve healthier population diets ${ }^{(10)}$. One of the most important food environments is the supermarket as this is the place where people in Western countries purchase most of their food ${ }^{(11)}$ (in NZ, $87 \%$ of people shop at a supermarket at least once per week $\left.{ }^{(12)}\right)$. 
Different aspects within supermarkets could influence consumer food choices, including the affordability of various foods ${ }^{(13)}$. Different studies have indicated that unhealthier food is relatively cheaper compared with more nutrient-dense food; in particular, foods high in fat and sugar have been found to be cheaper than less energydense foods ${ }^{(14-16)}$. While there is some debate in the literature about this topic ${ }^{(17)}$, there is consensus that price may form a barrier to buying healthier food, particularly for people with a low socio-economic status ${ }^{(18)}$.

Accessibility and availability of less healthy food also influence consumer food purchasing decisions. Due to technological innovations and agricultural subsidies, food has become more available, varied and affordable ${ }^{(19)}$. However, our food system is strongly commercial and economically driven ${ }^{(20)}$. This commercial focus produces an over-supply of dietary energy including from lownutrient crops such as sugar and corn ${ }^{(21)}$. Moreover, many of the products available are in processed form and contain excessive salt, sweeteners, refined grains and oils ${ }^{(22)}$. Evidence indicates that supermarkets in different developed countries display a large variety of processed foods high in sugars and fats and have more shelf space allocated to snack foods than to fresh fruit and vegetables ${ }^{(23)}$. In addition, global food manufacturers have a vested interest in the production and sale of ultra-processed foods because production costs are low and highly processed foods have a long shelf-life and a high retail value ${ }^{(24)}$.

Monteiro et al. describe a three-level classification system to categorize processed foods based on the applied industrial processes: (i) unprocessed or minimally processed; (ii) culinary processed; and (iii) ultra-processed food products $^{(5)}$. This classification system is used in the present study and is elaborated upon in the 'Methods' section.

The present study aims to use this classification to measure the packaged food environment in NZ supermarkets by examining the nutrient profiling score, price and product variety in relation to level of industrial processing. The study hypothesizes that foods with a higher level of industrial processes applied will be (i) less healthy, (ii) cheaper and (iii) more highly available compared with minimally processed foods.

\section{Methods}

\section{Data sources}

The NutriTrack database was used to examine the packaged food environment in NZ supermarkets. NutriTrack is an existing database developed by the University of Auckland to monitor the packaged food supply and identify opportunities for healthier reformulation of processed foods. Information is collected directly from all packaged supermarket products annually in four large NZ supermarkets in the Auckland region. In NZ, there is a duopoly in the retail market where the cooperatives
Foodstuffs and Progressive Enterprises Ltd control over $90 \%$ of the retail market ${ }^{(25)}$. NutriTrack collects data from the four largest franchises within these two cooperatives, and then the largest store for each chain, providing the widest product range. The NutriTrack database includes brand and package information and all nutrients present on the mandatory Nutrition Information Panel ${ }^{(26)}$ : energy $(\mathrm{kJ})$, protein $(\mathrm{g})$, carbohydrate $(\mathrm{g})$, sugar $(\mathrm{g})$ total fat $(\mathrm{g})$, saturated fat $(\mathrm{g})$ and sodium $(\mathrm{mg})$. Products are categorized into a food categorization system used by the Global Food Monitoring Group ${ }^{(27)}$. Categories include, for example, beverages, dairy, eggs, fish and fish products.

For the present study, NutriTrack 2011 and 2013 databases were used. NutriTrack 2013 (the most recent available) was used to gain insight into brand variety. However, price information was not included in NutriTrack 2013 and thus NutriTrack 2011, which contains price information, was used to gain insight into the healthiness and price. NutriTrack 2011 contains data collected from two major supermarket stores on 6020 packaged foods categorized into thirteen food categories and NutriTrack 2013 contains data collected from four major supermarket stores on 13406 products categorized into fifteen food categories.

\section{Measures}

\section{Level of processing}

A taxonomy developed by Monteiro et al. was used to categorize packaged foods into three levels of industrial processing: (i) unprocessed or minimally processed foods (group 1); (ii) processed culinary (group 2); and (iii) ultraprocessed foods (group 3) ${ }^{(5)}$. The industrial processes applied to the products in group 1 do not substantially alter the foods, whereas the processes applied to group 3 result in products with no resemblance to the original foods. For example, portioning, drying and freezing are industrial processes included in group 1. Group 2 includes for example pressured and milled products; and salting, baking and (deep) frying are examples of industrial processes applied to products placed in group $3^{(5)}$. For some of the food sub-categories the classification was ambiguous, these were: cream, plain dairy milk, other milk, nuts and fruit, and some processed meat products. For example, the sub-category 'other milk' contained coconut milk (group 2) and flavoured milks (group 3), but had to be classified as an entire category into only one of these groups. As a rule, when classifying a food sub-category that was ambiguous a conservative approach was taken where the sub-category was placed into a more industrial processed food group (Table 1).

\section{Price}

Three price measures were calculated for each individual product to enable a comprehensive review of price: energy cost $(\$ \mathrm{NZ} / 100 \mathrm{~kJ})$, unit cost $(\$ \mathrm{NZ} / 100 \mathrm{~g}$ or $\mathrm{ml})$ and serving cost $(\$ \mathrm{NZ} /$ serving). We consider $\$ \mathrm{NZ} /$ serving to be the 
Table 1 Packaged food products subdivided into three levels of processing

\begin{tabular}{clll}
\hline & \multicolumn{2}{c}{ Level of processing } \\
\cline { 2 - 5 } & Group 1: Minimally processed & $\begin{array}{l}\text { Group 2: Culinary } \\
\text { processed }\end{array}$ & Group 3: Ultra-processed \\
\hline $\begin{array}{c}\text { Included food } \\
\text { sub-categories }\end{array}$ & $\begin{array}{l}\text { Fruit and vegetable drinks, } \\
\text { water, eggs, bran, grains, } \\
\text { plain rice, chilled fish, frozen } \\
\text { fish, dried fruit, frozen fruit, } \\
\text { unsalted nuts, dried legumes } \\
\text { and vegetables, } \\
\text { unprocessed frozen } \\
\text { vegetables }\end{array}$ & $\begin{array}{l}\text { Flour, plain noodles, } \\
\text { plain pasta, fresh } \\
\text { pasta, sugar, plain } \\
\text { dairy milk, soya milk, } \\
\text { edible oils and oil } \\
\text { emulsions }\end{array}$ & $\begin{array}{l}\text { Cordial bases, electrolyte drinks, energy drinks, hot drink } \\
\text { mixes, ice tea drinks, soft and flavoured drinks, bread and } \\
\text { bakery products, breakfast cereals, cereal bars, flavoured } \\
\text { noodles, packet pasta, canned pasta, rice-based dishes, } \\
\text { rice crumbs, convenience foods, cheese, cream, desserts, } \\
\text { ice cream, condensed milk, flavoured dairy, other milk, } \\
\text { powdered milk, yoghurt, canned fish, fish with pastry, fruit } \\
\text { bars, dried fruit and nut mixes, fruit in juice/syrup, other fruit, } \\
\text { jam and spreads, nut and fruit bars, nut bars, nuts and fruit, } \\
\text { salted nuts, canned vegetables, frozen potato products, } \\
\text { processed frozen vegetables, pickled vegetables, meat } \\
\text { alternatives, processed meat, other deserts, sauces } \\
\text { spreads and seasonings, snack foods }\end{array}$ \\
\hline
\end{tabular}

most relevant, since the serving size is a standardized measure that makes it easier to compare similar foods ${ }^{(28)}$.

\section{Nutrient profiling score}

The Food Standards Australia New Zealand Nutrient Profiling Scoring Criterion (NPSC) ${ }^{(29)}$ was calculated for all products in order to determine their healthiness. The NPSC system allocates products an overall score based on both 'positive' and 'negative' nutrients including: energy (kJ), saturated fat, sugars, sodium, fibre, protein, and \% fruit, vegetable and nut content. The system is used to determine eligibility of foods to carry health claims in Australia and NZ. All foods and beverages are divided into three categories: category 1 includes beverages; category 2 includes any food not included in 1 or 3 ; and category 3 includes fats and oils. The scoring criteria differ for the three categories. Scores range between -10 and 28, with higher scores indicating a worse nutrient profile.

The NutriTrack 2011 data set did not contain all the required information to allocate the NPSC; fruit and vegetable percentage and (in the absence of a health claim) fibre content are not mandatory to list on NZ food products. Consequently, only 1518 of the 6020 products listed fibre on the Nutrition Information Panel. Indeed, two adaptions had to be made to the NPSC model ${ }^{(26)}$. First, since data on the fruit and vegetable percentage were missing, this component could not be used when calculating the NPSC. Second, since it can be expected that fibre is mostly listed in specific food categories (e.g. cereals), it was decided to exclude this from the NPSC to make the comparison between food categories more equitable. Sub-analysis revealed that this exclusion led to a slight increase in the mean NPSC from 3.6 to 5.9, meaning that the values used in our analysis will be slightly worse than the true NPSC.

\section{Product and brand variety}

All individual food products were categorized into three groups: (i) food manufacturer; (ii) brand; and (iii) subbrand. The NutriTrack 2013 database contained data on sub-brand (brand or logo which is listed on the front of package of the product ${ }^{(30)}$ ) but an Internet search was required to determine whether these sub-brands were stand-alone brands or part of an overarching brand. For example, Woolworths Select and Woolworths Homebrand are different brands on the package, but both belong to the overarching brand Woolworths. Next, the site of the Ministry of Economic Development ${ }^{(31)}$ was used to identify the food manufacturers behind these brands. This website lists all manufacturers active in the NZ food and beverage market. All brands that were not stand-alone were allocated to the higher-level food manufacturer. These food manufacturers were a combination of national and global acting companies. To assess the size of the food manufacturers, the number of products available in our supermarket sample was counted (i.e. in the present paper, product availability refers to the number of unique products, not the shelf inventory).

\section{Statistical analysis}

Statistical analyses were conducted using the statistical software package IBM SPSS Statistics version 22. Descriptive analyses were used to determine the number of unique products, energy costs, unit costs, serving costs and NPSC for the three levels of processing (groups 1, 2 and 3). An ANOVA $F$ test was used to compare the NPSC, energy costs, unit costs and serving costs across processed food groups. Prior to this test, the homogeneity of variance was tested and when there was variance between the groups, the Brown-Forsythe test was used instead. Bonferroni and Games-Howell post hoc tests were used relatively when variance was equal and with non-equal variance to determine which groups differed significantly from each other. For this test, food categories were required to have products in at least two of the three processed food groups. Five categories met this condition: beverages, cereals, dairy, fish and fish products, and fruit and vegetables. 
Next, the overall association between the NPSC and three price measures was explored using a linear regression model. Price was the dependent variable and the NPSC was the independent variable, adjusting for food category. These analyses were stratified by food category. Food categories containing $<150$ of the total 6020 products were considered too small to produce reliable estimates and were excluded. These categories were oils, eggs and other miscellaneous.

Sensitivity analysis was conducted to establish whether the classification of ambiguous food categories had any effect on results observed. In addition, analysis was repeated excluding beverages because their low energy density could impact observed associations between price and nutrient profiling scores ${ }^{(32)}$.

Finally, the overall brand variety, brand variety within the different processed food groups and brand variety within different food categories was explored using descriptive analysis. Distinctions were made between food manufacturers, brands and sub-brands. For these analyses, the focus was on the food categories most likely to be adversely associated with non-communicable diseases, including ready meals, crisps and snacks, biscuits, chocolates and sweets, breakfast cereals and soft drinks ${ }^{(33)}$.

\section{Results}

\section{Descriptive data}

The 2011 NutriTrack data set contained 6020 packaged food and beverage products with a mean NPSC score of $10 \cdot 58$ (SD 9.2). The mean energy cost was $\$ N Z 1 \cdot 17$ (SD 7.2) per $100 \mathrm{~kJ}$. The mean unit and serving costs were $\$ \mathrm{NZ} 1.77$ (SD 1.6) per $100 \mathrm{~g}$ and $\$ \mathrm{NZ} 1.06$ (SD 1.4) per serving, respectively).

NutriTrack 2013 contained data on 13406 packaged food products. The overall mean NPSC score of these products was 9.87 (SD 9.2).

\section{Nutrient profiling score and price for different levels of processed food}

Six hundred and twenty-two (10.3\%) packaged products were classified as minimally processed (group 1), 332 (5.5\%) as culinary processed (group 2) and 5066 (84.2\%) as ultra-processed foods (group 3). Table 2 shows the NPSC scores and costs for these three food groups.

The present study observed a difference in variance in NPSC scores between the three groups and therefore the Welch and Brown-Forsythe test was used, which supported the findings of the ANOVA in all cases. Results showed that the three processed food groups had statistically significantly different mean NPSC scores $(P<0.001)$ and the post hoc Games-Howell test showed that the mean for each group differed significantly from the mean for both other groups $(3 \times P<0 \cdot 001)$. The mean NPSC score was the lowest (best nutrient profile) in the minimally processed group (3.27) and highest in the ultra-processed group (11.63).

No statistically significant differences were found in energy cost by level of processing ( $P=0 \cdot 144$ ). However, significant differences were observed in unit cost between all groups $(3 \times P<0 \cdot 050)$; the ultra-processed group had the highest unit cost $(\$ N Z 1 \cdot 87 / 100 \mathrm{~g})$ and the culinary processed group had the lowest ( $\$ N Z 1 \cdot 02 / 100 \mathrm{~g}$ ). In addition, serving cost differed significantly between the minimally and culinary processed groups $(P<0.001)$, and between the culinary and ultra-processed groups $(P<0.001)$. The minimally processed group had the highest cost per serving with a mean of $\$ N Z 1 \cdot 16$ (SD 1.02) and the culinary processed group had the lowest cost with a mean of $\$ \mathrm{NZ} 0.64$ (SD 1.08) per serving (Table 2).

Differences in NPSC score and costs between the three levels of processing within five food categories are shown in Table 3. With the exception of fish and fish products and the culinary processed food category for cereals, the NPSC score was consistently higher (worse nutrient profile) for higher levels of processing. However, this difference was statistically significant only for beverages, cereals and dairy $(3 \times P<0.001)$. In addition, within the fish and fish products and fruit and vegetables categories, the energy cost $(P<0.001, P=0.517)$, unit cost $(P<0.007, P<0.001)$ and serving cost $(P<0 \cdot 001, P<0 \cdot 001)$ were consistently higher in the minimally processed food group (Table 3 ).

\section{Association between nutrient profiling score and price}

For all products combined, a significant linear relationship was found between NPSC score and all three price

Table 2 Nutrient profiling score and costs of 6020 packaged foods available for sale in New Zealand supermarkets in 2011

\begin{tabular}{|c|c|c|c|c|c|c|c|c|c|c|}
\hline & \multicolumn{9}{|c|}{ Level of processing } & \multirow{3}{*}{$\frac{\text { Overall ANOVA }}{P \text { value }}$} \\
\hline & \multicolumn{3}{|c|}{$\begin{array}{l}\text { Group 1: Minimally processed } \\
\qquad(n 622)\end{array}$} & \multicolumn{3}{|c|}{$\begin{array}{l}\text { Group 2: Culinary processed } \\
\qquad(n 332)\end{array}$} & \multicolumn{3}{|c|}{$\begin{array}{l}\text { Group 3: Ultra-processed } \\
\text { (n 5066) }\end{array}$} & \\
\hline & Mean & SD & $n$ & Mean & SD & $n$ & Mean & SD & $n$ & \\
\hline NPSC score & 3.27 & 5.68 & 609 & 7.95 & $10 \cdot 67$ & 327 & 11.63 & 8.95 & 5028 & $<0.001$ \\
\hline Energy cost (\$NZ/100 kJ) & 1.56 & 1.55 & 609 & 0.59 & 0.70 & 322 & $1 \cdot 16$ & $7 \cdot 86$ & 5061 & 0.144 \\
\hline Unit cost $(\$ N Z / 100 \mathrm{~g})$ & $1 \cdot 38$ & 1.53 & 622 & 1.02 & 1.03 & 332 & 1.87 & 1.67 & 5065 & $<0.001$ \\
\hline Serving cost (\$NZ/serving) & $1 \cdot 16$ & 1.02 & 621 & 0.64 & 1.08 & 329 & 1.07 & 1.44 & 5028 & $<0.001$ \\
\hline
\end{tabular}

NPSC, Nutrient Profiling Scoring Criterion, is used to determine the healthiness of products and ranges between -5 and 40 ; higher scores indicate less healthy products. 
measures. However, all associations were weak: energy cost: $B=-0.089, P<0 \cdot 001, R^{2}=0 \cdot 013$; unit cost: $B=0 \cdot 071$, $P<0.001, R^{2}=0.163$; serving cost: $B=-0.027, P<0.001$, $R^{2}=0 \cdot 031$. For all three price measures, food category was found to be an effect modifier and thus analyses were also conducted separately for each food category. These results are shown in Table 4. Again, most associations (twenty-six out of thirty) were weak, although a moderate association was found for dairy, beverages and fish.
For dairy, a negative association was observed between NPSC score and energy cost and a positive association with unit cost.

\section{Sensitivity analysis}

Sensitivity analyses to explore the impact of ambiguous classifications of food categories revealed similar results to the differences in NPSC score and energy cost between the

Table 3 Differences in energy, unit and serving costs according to level of processing across five food categories for 6020 packaged foods available for sale in New Zealand supermarkets in 2011

\begin{tabular}{|c|c|c|c|c|}
\hline \multirow[b]{3}{*}{ Food category } & \multicolumn{3}{|c|}{ Level of processing } & \multirow[b]{2}{*}{ ANOVA } \\
\hline & Group 1: Minimally processed & Group 2: Culinary processed & Group 3: Ultra-processed & \\
\hline & Mean & Mean & Mean & $P$ value \\
\hline \multicolumn{5}{|l|}{ Beverages } \\
\hline NPSC score & 1.40 & - & 4.46 & $<0.001$ \\
\hline Energy cost (\$NZ/100 kJ) & 2.69 & - & 11.65 & 0.002 \\
\hline Unit costs $(\$ / \mathrm{NZ100 \textrm {g } )}$ & 0.37 & - & 0.87 & $<0.001$ \\
\hline Serving costs ( $\$ N Z /$ serving) & 1.08 & - & 1.22 & 0.172 \\
\hline \multicolumn{5}{|l|}{ Cereals } \\
\hline NPSC score & $2 \cdot 38$ & $2 \cdot 31$ & 9.49 & $<0.001^{*}$ \\
\hline Energy cost $(\$ N Z / 100 \mathrm{~kJ})$ & 0.31 & 0.32 & 0.33 & 0.800 \\
\hline Unit costs $(\$ / N Z 100 \mathrm{~g})$ & 1.29 & 0.89 & 1.59 & $<0.001 \dagger$ \\
\hline Serving costs (\$NZ/serving) & 0.59 & 0.96 & 0.91 & 0.082 \\
\hline \multicolumn{5}{|l|}{ Dairy } \\
\hline NPSC score & - & -0.97 & $15 \cdot 21$ & $<0.001$ \\
\hline Energy cost (\$NZ/100 kJ) & - & 1.79 & 0.73 & $<0.001$ \\
\hline Unit costs $(\$ / N Z 100 \mathrm{~g})$ & - & 0.30 & 2.51 & $<0.001$ \\
\hline Serving costs (\$NZ/serving) & - & 0.67 & 1.02 & 0.001 \\
\hline \multicolumn{5}{|l|}{ Fish and fish products } \\
\hline NPSC score & $2 \cdot 14$ & - & 1.56 & 0.377 \\
\hline Energy cost (\$NZ/100 kJ) & 1.35 & - & 0.45 & $<0.001$ \\
\hline Unit costs $(\$ / \mathrm{NZ100} \mathrm{g})$ & $2 \cdot 61$ & - & 1.99 & 0.007 \\
\hline Serving costs ( $\$ N Z /$ serving) & $2 \cdot 27$ & - & 1.60 & $<0.001$ \\
\hline \multicolumn{5}{|l|}{ Fruit and vegetables } \\
\hline NPSC score & 5.73 & - & 6.57 & 0.087 \\
\hline Energy cost (\$NZ/100 kJ) & $1 \cdot 18$ & - & 1.08 & 0.517 \\
\hline Unit costs $(\$ / \mathrm{NZ100} \mathrm{g)}$ & 1.67 & - & $1 \cdot 11$ & $<0.001$ \\
\hline Serving costs ( $\$ N Z /$ serving) & 0.93 & - & 0.60 & $<0.001$ \\
\hline
\end{tabular}

NPSC, Nutrient Profiling Scoring Criterion, is used to determine the healthiness of products and ranges between -5 and 40 ; higher scores indicate less healthy products.

${ }^{*}$ Post hoc Games-Howell showed that NPSC score differed significantly $(P<0.050)$ between group 1 \& 3 and group 2 \& 3 .

†Post hoc Games-Howell showed that unit cost differed significantly $(P<0.050)$ between group $1 \& 2$ and group $2 \& 3$.

Table 4 Associations between nutrient profiling score (NPSC) and price by food category for 6020 packaged foods available for sale in New Zealand supermarkets in 2011

\begin{tabular}{|c|c|c|c|c|c|c|c|c|c|}
\hline \multirow[b]{2}{*}{ Food category } & \multicolumn{3}{|c|}{ Energy cost (\$NZ/100 kJ) } & \multicolumn{3}{|c|}{ Unit cost $(\$ N Z / 100 \mathrm{~g})$} & \multicolumn{3}{|c|}{ Serving cost (\$NZ/serving) } \\
\hline & $R^{2}$ & $B$ & $P$ value & $R^{2}$ & $B$ & $P$ value & $R^{2}$ & $B$ & $P$ value \\
\hline Beverages & 0.018 & -0.723 & 0.012 & $0.362^{*}$ & 0.147 & $<0.001$ & 0.058 & -0.046 & $<0.001$ \\
\hline Bread & 0.006 & -0.013 & 0.025 & 0.029 & 0.023 & $<0.001$ & 0 & 0 & 0.991 \\
\hline Cereal & 0.101 & -0.010 & $<0.001$ & $0 \cdot 122$ & 0.046 & $<0.001$ & 0.005 & -0.010 & 0.085 \\
\hline Convenience & 0.156 & -0.071 & $<0.001$ & 0.026 & 0.032 & 0.003 & 0.077 & -0.192 & $<0.001$ \\
\hline Dairy & $0.413^{*}$ & -0.032 & $<0.001$ & $0.411^{*}$ & 0.134 & $<0.001$ & 0.001 & 0.002 & 0.384 \\
\hline Fish & 0.028 & -0.029 & 0.011 & $0 \cdot 338^{*}$ & 0.206 & $<0.001$ & 0.087 & 0.067 & $<0.001$ \\
\hline Fruit and vegetables & 0.069 & -0.080 & $<0.001$ & 0.234 & 0.088 & $<0.001$ & 0 & -0.002 & 0.537 \\
\hline Meat & 0.048 & -0.023 & $<0.001$ & 0.055 & 0.065 & $<0.001$ & 0 & 0 & 0.980 \\
\hline Sauces and spreads & 0.046 & -0.154 & $<0.001$ & 0.012 & 0.024 & 0.002 & 0.075 & -0.043 & $<0.001$ \\
\hline Snack foods & 0.021 & -0.036 & 0.001 & 0.013 & 0.030 & 0.011 & 0 & -0.001 & 0.803 \\
\hline
\end{tabular}

NPSC, Nutrient Profiling Scoring Criterion, is used to determine the healthiness of products.

${ }^{\star}$ Moderate association between the nutrient profiling score and price. 
three groups. Further, analyses excluding beverages revealed similar results for the trend in NPSC score for the three different processed food groups. The analyses showed slightly different outcomes for the cost measures, but the directions of the associations stayed the same.

\section{Product and brand variety}

The NutriTrack 2013 database (13 406 products) was used to assess product variety. A total of thirty different food manufacturers were indicated as active in NZ, together producing $47.4 \%$ ( $n$ 6351) of all packaged food available in supermarkets. The two biggest food manufacturers were Foodstuffs (1079 products) and Woolworths Limited (729 products). Together these food manufacturers produced 1808 products, accounting for $13.5 \%$ of all packaged products available in supermarkets in NZ. The ten biggest food manufacturers produced 4707 products, accounting for $35 \cdot 1 \%$ of the products. When the study focused specifically only on ultra-processed foods, Foodstuffs ( $n$ 887) and Heinz ( $n$ 634) were the two single biggest food manufacturers producing $13.7 \%$ of all ultra-processed foods available in NZ supermarkets. The ten biggest food manufacturers within ultra-processed foods together produced $36.9 \%$ ( $n$ 4089) of ultra-processed foods.

The largest product variety was observed for ultraprocessed foods (11 085 products, $82.7 \%$ of total). Our analysis revealed that these products were produced by a relatively small number of manufacturers (Table 5). More detail on the product range for a set of key product categories that are linked to non-communicable diseases, i.e. breakfast cereals, biscuits, chocolates and sweets, ready meals, soft drinks, and crisps and snacks ${ }^{(32)}$, is provided in Table 5. For example, 311 breakfast cereal products were available, of which ninety-two (29.6\%) were produced by two food manufacturers, Ozone Organics and Kellogg's. Likewise, we observed 703 varieties of chocolates and sweets (6.3\% of all ultra-processed foods); 255 of these $(36.3 \%)$ were produced by two food manufacturers, Mondelèz/Kraft and Nestlé. Mondelèz/
Kraft produced these chocolates and sweets under nine different brands. Two hundred and seventy-four products were categorized as soft drinks and divided into two subcategories: sugar-free ( $n$ 44) and sugar-sweetened ( $n$ 230). Ninety-five $(34.7 \%)$ soft drinks were products by two food manufacturers, Coco Cola and PepsiCo.

\section{Discussion}

The present study aimed to map the packaged food environment in NZ supermarkets by examining the different levels of industrial food processing in relation to NPSC score, price and product variety. Our analyses showed a significant positive association between the level of industrial processing and NPSC score, indicating that ultraprocessed foods had a worse nutrient profile than culinary processed foods, which in turn had a worse nutrient profile than minimally processed foods. These findings confirm our hypothesis that highly processed foods have a worse nutrient profile. A large majority (83\%) of packaged products were classified as ultra-processed and our study found that relatively few food manufacturers produced a large number of products and brands. These results show there is clear potential to improve product availability in supermarkets, in particular by reducing the large variety of very similar ultra-processed foods.

Our findings support those of Monteiro and colleagues, who suggest that diet quality decreases when purchases of ultra-processed food increase ${ }^{(5)}$. In the present study we found that the NPSC score was significantly worse for ultra-processed foods compared with their less processed counterparts. This finding was consistent across and within food categories.

The original UK model ${ }^{(34)}$ upon which the NPSC was based states that if beverages score 1 or more and if foods score 4 or more, then these are classified as 'high in saturated fat, sodium or sugar'. The present study showed that, except for fish, for all food categories the mean NPSC score of ultra-processed foods clearly exceeded this value

Table 5 Number of product varieties and manufacturers per food sub-category for 13406 packaged foods available for sale in New Zealand supermarkets in 2013

\begin{tabular}{|c|c|c|c|c|c|}
\hline Food sub-category & $\begin{array}{l}\text { No. of } \\
\text { products }\end{array}$ & $\begin{array}{c}\text { Top two } \\
\text { manufacturers }\end{array}$ & $\begin{array}{l}\text { No. of brands owned by } \\
\text { manufacturer }\end{array}$ & $\begin{array}{l}\text { Produced no. of } \\
\text { products }\end{array}$ & $\begin{array}{l}\% \text { of total } \\
\text { products }\end{array}$ \\
\hline \multirow[t]{2}{*}{ Breakfast cereals } & 311 & Ozone Organics & 2 & 51 & $16 \cdot 4$ \\
\hline & & Kellogg's & 1 & 41 & $13 \cdot 2$ \\
\hline \multirow[t]{2}{*}{ Biscuits } & 696 & Campbell's & 1 & 121 & $17 \cdot 4$ \\
\hline & & Griffins & 3 & 104 & 14.9 \\
\hline \multirow[t]{2}{*}{ Chocolates \& sweets } & 703 & Mondelèz/Kraft & 9 & 189 & $26 \cdot 9$ \\
\hline & & Nestlé & 3 & 66 & 9.4 \\
\hline \multirow[t]{2}{*}{ Ready meals } & 294 & Heinz & 1 & 28 & 9.5 \\
\hline & & Hansells & 2 & 21 & $7 \cdot 1$ \\
\hline \multirow[t]{2}{*}{ Soft drinks } & 274 & Coca Cola & 3 & 67 & 24.5 \\
\hline & & PepsiCo & 4 & 28 & $10 \cdot 2$ \\
\hline \multirow[t]{2}{*}{ Crisps \& snacks } & 433 & PepsiCo & 6 & 99 & $22 \cdot 9$ \\
\hline & & Griffins & 2 & 65 & $15 \cdot 0$ \\
\hline
\end{tabular}


(beverages 4.46; cereals 9.49; dairy 15.21; fruit and vegetables 6.59). Since supermarkets are the most important point of food purchase ${ }^{(12)}$, the high availability of ultraprocessed foods is a major concern.

A review by Glanz et al. showed that increased availability of unhealthier foods in supermarkets increases sales ${ }^{(35)}$ and already ultra-processed foods contribute at least $60 \%$ of dietary intake in Western countries ${ }^{(36,37)}$. There are different interventions in the supermarket environment that could potentially reduce the consumption of these less healthy foods, including strategies focusing on the ' 4 P's' of the marketing mix: price, products, placement and promotion ${ }^{(35)}$. Promising strategies could be the reduction or relocation of unhealthier foods to less prominent shelf-space, the placement of healthier foods in more visible and accessible locations, reduction in promotion of high-fat, high-salt and high-sugar foods, and creating checkout aisles with healthier products ${ }^{(35)}$.

One aspect that could increase the attractiveness of ultra-processed foods is affordability. However, in contrast to our hypothesis, in the present study we found no clear patterns in the association between price (energy cost, unit cost or serving cost) and level of processing. Our study did find some patterns within specific food categories, where the energy, unit and serving costs were higher for minimally $v$. ultra-processed fish and fruit and vegetables. Likewise, our study did not find a strong association between the healthiness (NPSC) of products and their price. We did find some statistically significant associations for energy cost and serving cost, which were both negatively correlated with NPSC score, but these were very weak. This supports the findings by Ni Mhurchu and Ogra, who stated it is possible in NZ to improve diet quality with comparable but healthier products without also increasing the cost of the diet (e.g. moving from ultra-processed to minimally processed) ${ }^{(38)}$.

Many other studies in the literature, however, report that healthier foods tend to cost more ${ }^{(16,28,39)}$. A possible explanation for the difference in findings of our study compared with this previous work could be that they mostly used energy density to classify the healthiness of products $^{(16,28,39)}$, while we used nutrient profiling. It can be argued that nutrient profiling is a better method, since it takes a more complete approach to the healthiness of food by looking not only at energy levels, but also at saturated fat, added sugars, salt levels and protein. However, not only the absolute price is important to consider, but also the price of convenience ${ }^{,(40)}$. Ultra-processed foods are more convenient and require less preparation, cooking skills and time compared with less processed foods and people are prepared to pay for this ${ }^{(40)}$. Since our study did not observe significant absolute cost differences between minimally and ultra-processed foods, it can be argued that they still could be perceived cheaper in terms of value for money ${ }^{(40)}$.

The present study found that $35 \%$ of all packaged foods available in NZ supermarkets were produced by the ten biggest food manufacturers. This is comparable to numbers from the USA showing that $32 \%$ of the packaged food is produced by the ten biggest food manufacturers ${ }^{(24)}$. Similar trends were observed within food categories. For example, our study observed that one manufacturer produced 189 (27\% of total) chocolates and sweets displayed through nine different brands. Furthermore, we found that a large number ( $n$ 1079, $n$ 729) of food products were manufactured by the two largest supermarkets themselves (Foodstuffs and Progressive Enterprises Ltd). Together these supermarkets represent the largest food-producing manufacturers ( $14 \%$ of all products), meaning that these two supermarkets do not only own $90 \%$ of the market share, but also predominantly produce and sell their own products. These numbers suggest that there are strong incentives for manufacturers to produce many varieties of basically the same processed foods. Stuckler and colleagues gave three explanations for this phenomenon: low production costs, long shelf-life and high retail value ${ }^{(24)}$.

To our knowledge the present study is the first that gives detailed insight into the availability, variety and healthiness of different processing levels of packaged foods available in supermarkets. However, there are some limitations that are important to consider. First, it is important to acknowledge the limitations of the three-tier taxonomy used to classify processed food products ${ }^{(5)}$. The processes making products eligible for inclusion in the ultra-processed food group were much broader than the processes for the minimally and culinary processed food groups. This could be a reason why the ultra-processed food group included substantially more products ( $n$ 5066) than the two other levels ( $n 662$ and 332, respectively). However, the method of classification had been validated and used in other studies ${ }^{(33,36,41)}$. To the best of our knowledge no other taxonomies exist to classify food by level of processing. Further, our sensitivity analyses, where fewer products were classified as ultra-processed, revealed similar results as the main analyses. Another limitation is that our study focused exclusively on packaged foods. Therefore it does not provide insight into the complete supermarket environment which also includes fresh produce (e.g. fresh fruits and vegetables, raw nuts, etc.) and thus is healthier than the supermarket environment presented here. However, our study does highlight how unhealthy most packaged foods available in supermarkets are. While the availability of more healthy foods is important, recent evidence shows that when both healthy and less healthy foods are highly available (as in supermarkets) this still has negative consequences for obesity ${ }^{(35)}$.

A strength of the current research was the use of the NutriTrack database. This database is unique in that it contains nutrient information on all packaged foods for sale in major NZ supermarkets, including brand details. Data are collected annually based on a published proto$\mathrm{Col}^{(27)}$ and data collection is undertaken in the four biggest supermarket stores in the largest city in NZ. The use of the 
NPSC nutrient profiling model is another strength of our study. This is a rigorous method of assessing the healthiness of foods as it looks at both positive and negative nutrients. Unfortunately, we were not able to include all aspects of the NPSC score, such as fibre and \% fruit, vegetable and nut, meaning that the true values might be healthier than the ones presented here. However, since this information was left out consistently, all products were affected equally, meaning that it likely did not affect reported differences between groups.

Finally, it is possible we might have misclassified some products in relation to their producing food manufacturers. However, the study used a quality database from the Ministry of Economic Development of NZ and most products were easy to track. In addition, the results are aligned with American data which gives us confidence that the results are valid.

Our study reveals there are clear opportunities to improve the packaged food environment in supermarkets, in particular with regard to the availability of ultraprocessed foods. One strategy to achieve this is via voluntary industry $\operatorname{codes}^{(42)}$. A study by Stuben et al. showed that if food manufacturers were interested in improving the nutritional quality of their products, this could have lasting positive impacts on population BMI. However, that same study also revealed that these efforts would decrease their market share in low nutritional quality products in the long term, which explains the low interest of food manufacturers in reformulating their products ${ }^{(42)}$. Food manufacturer initiatives supported by governmental regulation are therefore expected to be more effective in creating a healthier food environment. To achieve this, governments should take a leading role ${ }^{(43)}$.

\section{Conclusion}

The majority of packaged foods in NZ supermarkets are ultra-processed and these foods are also the least healthy. The present study found no significant price difference between ultra- and less processed foods, indicating ultraprocessed foods might provide time-poor consumers with more value for money. There is a vast range of product and brand varieties of essentially the same product and these are produced by a relatively small number of manufacturers, including supermarket-owned brands. These findings highlight a clear need for improvement of the supermarket packaged food environment, where we should focus on displaying a smaller number of less healthy ultra-processed foods and more healthy products, and increase efforts to reformulate products to make them healthier.

\section{Acknowledgements}

Financial support: This research received no specific grant from any funding agency in the public, commercial or not-for-profit sectors. Conflict of interest: None. Authorship: C.M.L. designed and carried out the study, as well as conducted the data analyses and wrote the article. I.H.M.S. supervised the designing and carrying out of the study, as well as giving feedback on the writing. H.E. and C.N.M. gave permission to use the NutriTrack data set and both provided feedback on the article. W.E.W. formulated the research question and supervised the carrying out of the study, in addition to writing parts of the article. Ethics of human subject participation: Ethical approval was not required.

\section{References}

1. Ministry of Health (2013) Health Loss in New Zealand: A Report from the New Zealand Burden of Diseases, Injuries and Risk Factors Study, 2006-2016. Wellington: Ministry of Health.

2. Lim SS, Vos T, Flaxman AD et al. (2012) A comparative risk assessment of burden of disease and injury attributable to 67 risk factors and risk factor clusters in 21 regions, 1990-2010: a systematic analysis for the Global Burden of Disease Study 2010. Lancet 380, 2224-2260.

3. Scarborough P, Nnoaham KE, Clarke D et al. (2010) Modelling the impact of a healthy diet on cardiovascular disease and cancer mortality. J Epidemiol Community Health 66, 420-426.

4. Stefanogiannis N, Lawes CM, Turley M et al. (2005) Nutrition and the burden of disease in New Zealand: 1997-2011. Public Health Nutr 8, 395-401.

5. Monteiro CA, Levy RB, Claro RM et al. (2010) A new classification of foods based on the extent and purpose of their processing. Cad Saude Publica 26, 2039-2049.

6. Regmi A \& Gehlhar M (2005) Processed food trade pressured by evolving global supply chains. Amber Waves 3 , 12-19.

7. Slimani N, Deharveng G, Southgate DA et al. (2009) Contribution of highly industrially processed foods to the nutrient intakes and patterns of middle-aged populations in the European Prospective Investigation into Cancer and Nutrition study. Eur J Clin Nutr 63, Suppl. 4, S206-S225.

8. Monteiro CA (2009) Nutrition and health. The issue is not food, nor nutrients, so much as processing. Public Health Nutr 12, 729-731.

9. Rekhy R \& McConchie R (2014) Promoting consumption of fruit and vegetables for better health. Have campaigns delivered on the goals? Appetite 79, 113-123.

10. Cohen DA (2008) Obesity and the built environment: changes in environmental cues cause energy imbalances. Int J Obes (Lond) 32, Suppl. 7, S137-S142.

11. Escaron AL, Meinen AM, Nitzke SA et al. (2013) Supermarket and grocery store-based interventions to promote healthful food choices and eating practices: a systematic review. Prev Chronic Dis 10, E50.

12. Murray SJ (2012) Shopping Behaviours of New Zealand Households. Wellington: Health Sponsorship Council.

13. Story M, Kaphingst KM, Robinson-O'Brien R et al. (2008) Creating healthy food and eating environments: policy and environmental approaches. Annu Rev Public Health 29, $253-272$

14. Drewnowski A \& Specter S (2004) Poverty and obesity: the role of energy density and energy costs. Am J Clin Nutr $\mathbf{7 9}$, 6-16.

15. Powell LM, Auld MC, Chaloupka FJ et al. (2007) Access to fast food and food prices: relationship with fruit and vegetable consumption and overweight among adolescents. Adv Health Econ Health Serv Res 17, 23-48. 
16. Waterlander WE, de Haas WE, van Amstel I et al. (2010) Energy density, energy costs and income - how are they related? Public Health Nutr 13, 1599-1608.

17. Lipsky LM (2009) Are energy-dense foods really cheaper? Reexamining the relation between food price and energy density. Am J Clin Nutr 90, 1397-1401.

18. Steenhuis IH, Waterlander WE \& de Mul A (2011) Consumer food choices: the role of price and pricing strategies. Public Health Nutr 14, 2220-2226.

19. Tillotson JE (2004) America's obesity: conflicting public policies, industrial economic development, and unintended human consequences. Annu Rev Nutr 24, 617-643.

20. Pinstrup-Andersen P (2002) Food and agricultural policy for a globalizing world: preparing for the future. Am J Agric Econ 84, 1201-1214.

21. Schafer Elinder L, Lock K \& Blenkus G (2006) Public health, food and agriculture policy in the European Union. In Health in all Policies Prospects and Potentials, pp. 93-110 [T Stahl, M Wismar, E Ollili et al., editors]. Helsinki: Ministry of Social Affairs and Health.

22. Nugent R (2011) Bringing Agriculture to the Table. How Agriculture and Food Can Play a Role in Preventing Chronic Disease. Chicago, IL: Chicago Council on Global Affairs.

23. Thornton LE, Cameron AJ, McNaughton SA et al. (2013) Does the availability of snack foods in supermarkets vary internationally? Int J Behav Nutr Phys Act 10, 56.

24. Stuckler D, McKee M, Ebrahim S et al. (2012) Manufacturing epidemics: the role of global producers in increased consumption of unhealthy commodities including processed foods, alcohol, and tobacco. PLoS Med 9, e1001235.

25. Bava CM, Jaeger SR \& Dawson J (2009) In-store influences on consumers' grocery purchasing decisions: a qualitative investigation. J Custom Behav 8, 221-236.

26. Health Agency (2013) Australia New Zealand Food Standards Code - Nutrition Information Reguirements: Australian Government ComLaw. http://www.comlaw.gov. au/Details/F2013C00098 (accessed June 2014).

27. Dunford E, Webster J, Metzler AB et al. (2012) International collaborative project to compare and monitor the nutritional composition of processed foods. Eur J Prev Cardiol 19, 1326-1332.

28. US Food and Drug Administration (2014) How to Understand and Use the Nutrition Facts Label. http://www.fda. gov/Food/IngredientsPackagingLabeling/LabelingNutrition/ ucm274593.htm\#serving_size (accessed March 2015).

29. Food Standards Australia New Zealand (2013) Short guide for industry to the Short guide for industry to the Nutrient Profiling Scoring Criterion (NPSC) in Standard 1.2.7 Nutrition, Health and Related Claims. http://www.foodstandards.gov.au/industry/labelling/Documents/Short-guidefor-industry-to-the-NPSC.pdf (accessed June 2015).
30. Vandevijvere S \& Swinburn B (2014) Towards global benchmarking of food environments and policies to reduce obesity and diet-related non-communicable diseases: design and methods for nation-wide surveys. BMJ Open $\mathbf{4}$, e005339.

31. New Zealand Food \& Beverage, Ministry of Economic Development (2014) The Food \& Beverage Directory. http://directory.foodandbeverage.govt.nz/ (accessed June 2014).

32. Drewnowski A (2010) The cost of US foods as related to their nutritive value. Am J Clin Nutr 92, 1181-1188.

33. Moodie R, Stuckler D, Monteiro C et al. (2013) Profits and pandemics: prevention of harmful effects of tobacco, alcohol, and ultra-processed food and drink industries. Lancet $\mathbf{3 8 1}$, 670-679.

34. Rayner M, Scarborough P, Stockley L et al. (2005) Nutrient Profiles: Further Refinement and Testing of Model SSCg3d. Oxford: British Heart Foundation Health Promotion Research Group, Department of Public Health, University of Oxford.

35. Glanz K, Bader MD \& Iyer S (2012) Retail grocery store marketing strategies and obesity: an integrative review. $\mathrm{Am} \mathrm{J}$ Prev Med 42, 503-512.

36. Moubarac JC, Martins AP, Claro RM et al. (2013) Consumption of ultra-processed foods and likely impact on human health. Evidence from Canada. Public Health Nutr 16, 2240-2248.

37. Slimani N, Deharveng G, Southgate D et al. (2009) Contribution of highly industrially processed foods to the nutrient intakes and patterns of middle-aged populations in the European Prospective Investigation into Cancer and Nutrition study. Eur J Clin Nutr 63, Suppl. 4, S206-S225.

38. Mhurchu CN \& Ogra S (2007) The price of healthy eating: cost and nutrient value of selected regular and healthier supermarket foods in New Zealand. N Z Med J 12, U2388.

39. Maillot M, Darmon N, Darmon M et al. (2007) Nutrientdense food groups have high energy costs: an econometric approach to nutrient profiling. J Nutr 137, 1815-1820.

40. Brunner TA, Van der Horst K \& Siegrist M (2010) Convenience food products. Drivers for consumption. Appetite 55, 498-506.

41. Tavares LF, Fonseca SC, Garcia Rosa ML et al. (2012) Relationship between ultra-processed foods and metabolic syndrome in adolescents from a Brazilian Family Doctor Program. Public Health Nutr 15, 82-87.

42. Struben J, Chan D \& Dube L (2014) Policy insights from the nutritional food market transformation model: the case of obesity prevention. Ann N Y Acad Sci 1331, 57-75.

43. Swinburn BA, Sacks G, Hall KD et al. (2011) The global obesity pandemic: shaped by global drivers and local environments. Lancet 378, 804-814. 